\title{
Therapeutic concentrations of glucagon-like peptide-1 in cerebrospinal fluid following cell- based delivery into the cerebral ventricles of cats
}

Silke Glage ${ }^{1}$, Petra M Klinge ${ }^{2}$, Miles C Miller ${ }^{2}$, Christine Wallrapp ${ }^{4}$, Peter Geigle ${ }^{4}$, Hans J Hedrich ${ }^{1}$ and Thomas Brinker $2,3^{*}$

\begin{abstract}
Background: Neuropeptides may have considerable potential in the treatment of acute and chronic neurological diseases. Encapsulated genetically engineered cells have been suggested as a means for sustained local delivery of such peptides to the brain. In our experiments, we studied human mesenchymal stem cells which were transfected to produce glucagon-like peptide-1 (GLP-1).

Methods: Cells were packed in a water-permeable mesh bag containing 400 polymeric microcapsules, each containing 3000 cells. The mesh bags were either transplanted into the subdural space, into the brain parenchyma or into the cerebral ventricles of the cat brain. Mesh bags were explanted after two weeks, and cell viability, as well as GLP-1 concentration in the cerebrospinal fluid (CSF), was measured.

Results: Viability of cells did not significantly differ between the three implantation sites. However, CSF concentration of GLP-1 was significantly elevated only after ventricular transplantation with a maximum concentration of $73 \mathrm{pM}$ (binding constant $=70 \mathrm{pM}$ ).

Conclusions: This study showed that ventricular cell-based delivery of soluble factors has the capability to achieve concentrations in the CSF which may become pharmacologically active. Despite the controversy about the pharmacokinetic limitations of ventricular drug delivery, there might be a niche in this for encapsulated cell biodelivery of soluble, highly biologically-effective neuropeptides of low molecular weight like GLP-1.
\end{abstract}

\section{Background}

Neurotrophic peptides may have considerable potential in the treatment of acute and chronic neurological diseases. However, systemic delivery is limited by significant systemic side effects, short plasma half-life or poor bloodbrain barrier passage. Therefore, local administration into the central nervous system (CNS) has been proposed [1,2]. However, this drug delivery route, bypassing the blood brain barrier, has been challenged, because substances are rapidly removed from the brain through physiological cerebrospinal fluid (CSF) outflow pathways [3-5].

Ex vivo gene therapy using encapsulated cell biodelivery has been suggested as a way to achieve a more sustained local delivery of proteins into the CNS. Bankable, non-

\footnotetext{
* Correspondence: thbrinker@gmail.com

${ }^{2}$ Neurosurgery Foundation, 55 Claverick Str., Providence, RI 02903, USA Full list of author information is available at the end of the article
}

autologous cell lines cells can be used, that have been genetically engineered to produce the protein. To prevent host versus graft reaction, encapsulation of those cells with permselective membranes has been introduced, to allow diffusional nutrition and the outward passage of the recombinant protein [6]. Encapsulation has been achieved with different techniques, using either hollow fibers or spherical polymeric microcapsules. Hollow fiber encapsulated cells were investigated in clinical trials after implantation into the lumbar subarachnoid space in chronic pain [7] and ALS patients [8] as well as into the lateral ventricle in Huntington's disease patients [9]. While lumbar implantation resulted in excellent cell viability and significant lumbar CSF levels of the secreted soluble factors [7], ventricular implantation has shown disappointing results with variable numbers of surviving cells along with a markedly low secretory rate [9]. Spherical microcapsules may
C Biomed Central

ㄷ 2011 Glage et al; licensee BioMed Central Ltd. This is an Open Access article distributed under the terms of the Creative Commons Attribution License (http://creativecommons.org/licenses/by/2.0), which permits unrestricted use, distribution, and reproduction in any medium, provided the original work is properly cited. 
achieve improved viability rates because their shape provides almost ideal diffusion properties which can improve the nutrition of encapsulated cells $[10,11]$.

Glucagon-like peptide-1 (GLP-1) is a neuroprotective substance which has been shown to protect neurons from amyloid toxicity in vitro as well as in vivo in Alzheimer's disease models $[12,13]$. Recently, in a rat model of traumatic brain injury, our group has demonstrated similar neuroprotective properties where GLP-1 was delivered from mesenchymal stem cells (MSC) encapsulated in alginate microspheres. After intraventricular implantation of the cells, GLP-1 concentration in the CSF was increased up to $17 \mathrm{pM}$, while no increased GLP-1 levels were found after transplantation of MSC cell capsules without GLP-1 secretion [14]. Using the same cell capsules in a double transgenic mouse model of Alzheimer's disease, we found a significant anti-inflammatory effect with GLP-1 engineered MSCs, but not with MSC without GLP-1 secretion [15]. To provide further evidence for encapsulated cell biodelivery of neurotrophic substances for clinical applications, the present experiment investigated the viability and secretory activity of cells as well as the cisterna magna CSF level of GLP-1 after cerebral transplantation of GLP-1 producing MSC in an animal model with a larger brain. Three different implantation sites in the cat brain were compared: intraventricular, subdural and intraparenchymal.

\section{Methods}

\section{Alginate microcapsules and mesh enclosure}

A human, bone marrow-derived, mesenchymal stem cell line, manufactured under good manufacturing practice (GMP) conditions, was used in this study. It was immortalized by transduction with the human telomerase reverse transcriptase (hTERT) gene [16]. After transfection with a plasmid vector encoding a GLP-1 fusion gene, the cells produced an $8.7 \mathrm{kDa}$ dimeric GLP-1 molecule. The cells are embedded in a spherical shaped alginate matrix (about $600 \mu \mathrm{m}$ in diameter). The alginate matrix is generated by cross-linking alginate with barium ions. The alginate itself has no pharmacological effect but provides a mechanical scaffold for the cells and protects them against attacks by the host's immune system. Subsequent to the alginate encapsulation process, the cell capsules were stored in liquid $\mathrm{N}_{2}$ until usage. Each capsule contained about 3000 cells. Alginate encapsulation and cell engineering are proprietary manufacturing techniques of CellMed AG, Alzenau, Germany (figure 1).

The alginate capsules containing the mesenchymal stem cells were packed within a $1 \times 1 \mathrm{~cm}$ sized, manually sutured bag using a polypropylene mesh (MB-Mesh 40 Super Light, Medical Biomaterial Products GmbH, Germany). For implantation, $400 \pm 100$ capsules were thawed and filled into this mesh bag (figure 2). Transplantation within the bag allows for the immobilization of the cell capsules at different intracranial implantation sites. A vicryl thread was attached to the mesh bag to allow retrieval.

\section{Experimental protocol and surgical techniques (implantation and explantation)}

Thirteen cats (European Shorthair, Central Animal Facility, Hannover, Medical School) were used for the experiments. All experimental procedures were performed under general anaesthesia. It was initiated by s.c. injection of a ketaminhydrochloride / xylazine premedication (per kg: $0.1 \mathrm{ml} \mathrm{Ketamin} \mathrm{Gräub}{ }^{\circledR}$, Dr. E. Gräub AG, Bern, Switzerland; 0,05 ml Rompun ${ }^{\circledR}$, Bayer, Leverkusen, Germany). Subsequently the animals received

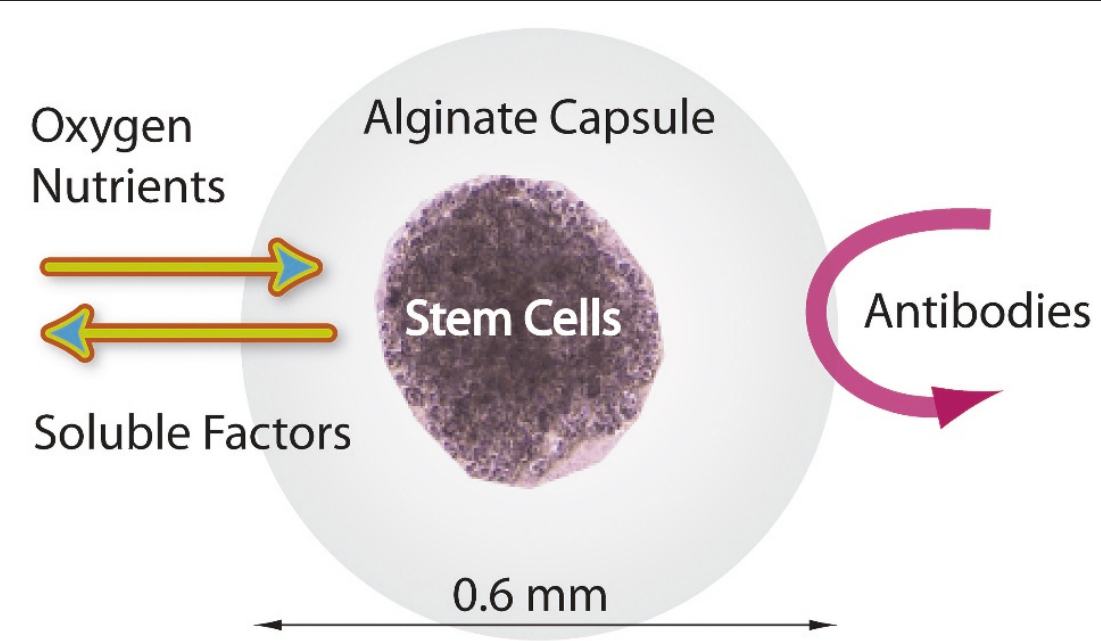

Figure 1 Illustration of cell encapsulation technology. Cells are embedded within a polymeric matrix, which is surrounded by an outer cellfree capsule. Smaller molecules diffuse through the capsule, while at the same time, larger proteins and cells are excluded. 


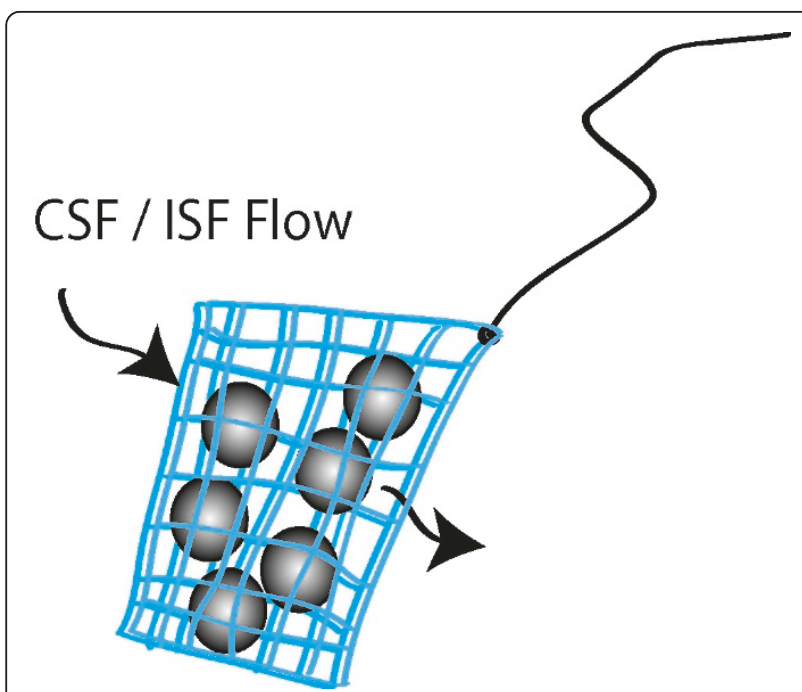

Figure 2 Diagram of the mesh enclosure. Several hundreds of cellcontaining capsules are packaged in a mesh enclosure that is permeable to fluids. Volumetric flow of cerebrospinal or interstitial fluid through the pores of the mesh supplies internal cells with oxygen and nutrients.

2-6ml propofol i.v. (Propofol-Lipuro ${ }^{\circledR}$, B.Braun Melsungen AG, Germany) and, after endotracheal intubation, isoflurane 1.5-2.5\% (Forene ${ }^{\circledR}$, Abbot, Baar, Switzerland). All animals received an antibiotic prophylaxis for 10 days (extended-release penicillin und Dihydrostreptomy$\operatorname{cin}^{\circledR}$, Chassot) as well as an analgetic therapy 3 days post operation (initially $4 \mathrm{mg} / \mathrm{kg}$, then $2 \mathrm{mg} / \mathrm{kg}$ Carprofen s.c., Buprenorphin $0.01 \mathrm{mg} / \mathrm{kg}$ ).

A $0.5 \times 1.5 \mathrm{~cm}$ frontal craniotomy was performed under sterile conditions below the temporal muscle insertion. A straight dural opening $1.5 \mathrm{~cm}$ in length was made. The mesh bag containing the microcapsules was implanted into the subdural $(n=4)$, the frontal intraparenchymal $(n=5)$ or the intraventricular $(\mathrm{n}=4)$ space. After a frontal cortisectomy, a subcortical pocket was created for the intraparenchymal placement and a transcortical approach to the frontal horn for the intraventciular implantation of the cell container. Care was given to sufficient hemostasis with bipolar cautery. The dural opening was sealed with absorbable gelatin compressed sponge and the craniectomy was closed with bone wax. The vicryl thread, which was attached to the mesh implant, was incorporated into the bone wax for fixation. The temporal muscle was then reapproximated using 0.3 vicryl sutures and skin was closed with 0.3 monocryl sutures. Antibiotics were given for 10 days post-surgery. The animals were weighed and checked for clinical and neurological symptoms on a daily basis.

Explantation of the mesh was performed after 14 days. The implantation site was explored under general anaesthesia and, once the end of the thread attached to the mesh beg was exposed, the implant was explanted with gentle traction. Blood samples were taken by percutaneous puncture of a forelimb vein, and CSF was collected by percutaneous puncture of the cisterna magna; samples were taken in the subdural and intracerebral implantation group only at day 14 , and additionally in the ventricular implantation group at days 0 and 7 . After centrifugation, a dipeptidyl peptidase IV inhibitor was added (\#DPP4, Biotrend), and the samples were frozen at $-80^{\circ} \mathrm{C}$ until the active GLP-1 was measured by ELISA (Linco, EMD Millipore).

This study was conducted in accordance with the German animal protection law and with the European Communities Council Directive 86/609/EEC for the protection of animals used for experimental purposes. All experiments were approved by the Local Institutional Animal Care and Research Advisory Committee and permitted by the local government (33-42502-06/ 1133).

\section{Assessment of stem cell viability during and post- implantation and histological assessment of the implantation site}

The explanted cell capsules were recultured and the postimplantation GLP-1 production rate was determined by active GLP-1 ELISA (Linco, EMD Millipore), and compared with the GLP-1 secretion rate prior to implantation. An amount of 10 capsules per explanted containment was transferred into $1 \mathrm{ml}$ of culture medium (EMEM, 10\% BGS, 2mM L-glutamine) and incubated for $90 \mathrm{~min}$. Capsules were further assessed for viability with SYBR green/ propidium iodide staining. After intravital intracardiac perfusion under deep anaesthesia, brains were removed and fixed in $4 \%$ paraformaldehyde for histological analysis with hematatoxylin and eosin (H\&E) staining.

\section{Results}

\section{GLP-1 CSF concentrations and stem cell viability}

Table 1 summarizes GLP-1 concentrations in CSF and blood plasma, comparing the measures after subdural, intraparenchymal and intraventricular implantation. Cell viability, as obtained by the GLP-1 production rate of stem cells and by the SYBR Green/propidium iodide staining at day 1 post-explantation, is also shown. Viability of cells did not significantly differ between the three implantation sites. Increased GLP-1 concentrations were only found in the CSF, but not in the blood plasma, and only after intra-ventricular implantation both at 7 and 14 days following implantation.

\section{Histological findings at the implantation site}

Gross macroscopic observation of the explanted brains did not show any significant haemorrhages, midline shifts or signs of infection at the surgical sites. None of the animals exhibited acute occlusive hydrocephalus. 
Table 1 CSF and serum concentrations of glucagon-1 and cell viability following implantation of encapsulated genetically-engineered stem cells into three intracerebral sites in cats

\begin{tabular}{|c|c|c|c|}
\hline Implantation Site & Subdural $(n=4)$ & Intracerebral $(n=5)$ & Intraventricular $(n=4)$ \\
\hline CSF GLP-1 concentration [pM] & $\begin{array}{l}\text { 14d: } \\
2.3 / 2.5 /<2 / 2.2\end{array}$ & $\begin{array}{l}14 \mathrm{~d}: \\
<2 /<2 /<2 /<2 /<2\end{array}$ & $\begin{array}{l}\text { Day zero: }<2 /<2 /<2 /<2 \\
\text { 7d: } N A^{* *} / 63 / 6 / 73 \\
\text { 14d: } 47 / 44 / 8 /<2\end{array}$ \\
\hline Serum GLP-1 concentration [pM] & NA & NA & $\begin{array}{l}\text { Day zero: <2.5(all) } \\
7 \mathrm{~d}:<2.5(\text { all) } \\
14 \mathrm{~d}:<2.5(\mathrm{all})\end{array}$ \\
\hline GLP-1 secretion prior to implantation (fmol/h/capsule) & 3.6 (all) & 4.6 (all) & 4.6 (all) \\
\hline GLP-1 secretion post implantation (fmol/h/capsule) & $N A^{*} / N A^{*} / 0.6 / 3.0$ & $1.6 / 1.2 / 1.6 / 1.7 / 3.5$ & $0.9 / 1.6 / 1.5 / 1.9$ \\
\hline Viability of cells / capsule (SYBRGreen/ propidium iodide) & $N A^{*} / N^{*} /<10 \% / 40 \%$ & $53 \% / 58 \% / 20 \% / 83 \% / 70 \%$ & $41 \% / 52 \% / 51 \% / 53 \%$ \\
\hline
\end{tabular}

Figure 3 shows representative H\&E stains for all three implantation sites. H\&E staining did not reveal a major local glial or inflammatory tissue response which could have ensheathed the implants. Also, while showing some minor fresh hemorrhages as a result of the surgical retrieval of the mesh bag, the $H \& E$ staining ruled out major local tissue injury.

\section{Discussion}

The present study investigates the CSF concentrations of the GLP-1 peptide after implantation of GLP-1 producing encapsulated MSC into the subdural, intraparenchymal and intraventricular space of the cat brain. While viability of cells retrieved after two weeks of implantation did not differ between the implantation sites, the levels of GLP-1 in the CSF were increased after ventricular, but not after subdural or intraparenchymal transplantation. After ventricular implantation, the measured CSF concentrations of GLP-1 reached the level of the binding constant of the GLP-1 receptor [17].

\section{GLP-1}

GLP-1 is an endogenous insulin-stimulating peptide secreted from the gastrointestinal tract in response to food intake [18]. GLP-1 receptors are also expressed throughout the mammalian brain [19]. Stimulation of these receptors is associated with neuroprotective and neurotrophic activity $[12,13]$. GLP-1 also improves learning and memory, which was shown in GLP-1 receptor-deficient mice [20]. Because the plasma half-life of GLP-1 averages only one to two min, the substance must be locally delivered to the brain despite its good blood brain barrier permeability [21].

We show here that encapsulated cell biodelivery can achieve potentially therapeutic CSF concentration of GLP-1. Our experimental design did not include control groups i.e. capsules with mesenchymal cells but without GLP-1 secretion, because previous experiments in rodents have already shown that only GLP-1 engineered cells, but not native MSCs, achieved increased CSF levels of the peptide [14]. Furthermore, ELISA measurements in the double transgenic mouse model of Alzheimer's disease revealed increased brain tissue concentrations of GLP-1 only after transplantation of GLP-1-secreting capsules. Interestingly, in the transgenic mice a baseline level of GLP-1 was found in untreated control animals as well as after transplantation of MSC without GLP-1 secretion [15]. That increased CSF levels could have resulted from the surgical implantation procedure and the related brain lesion in these experiments, appears to be unlikely as in the traumatic brain injury model we found no increased CSF level of GLP-1 as a result of the brain damage alone [14].

\section{Viability and secretory activity of retrieved cell capsules}

In vitro experiments have shown that CSF can serve as a carrier for cellular nutrients [22]. Accordingly, studies in rodents have shown preserved viability and secretory activity after cerebral long-term implantation of microencapsulated cells $[10,23]$. In our cat experiments, we found viability and recorded secretory rates in the retrieved cells, which were as high as those after cerebral transplantation in rodents [14]. The present results indicate that a volumetric flow rate of cerebrospinal or interstitial fluid through the mesh pores exists and that it is sufficient for in vivo nutrient and oxygen supply to the encapsulated cells inside the mesh bag. Overall, the highest viability and secretory rates were observed with intraparenchymal transplantation, while after subdural placement they were fairly low. Our present results correspond well to our previous findings in rodents, showing that the secretory activity decreases with the implantation time [14]; future experiments must clarify how long the secretory activity lasts.

\section{Implantation site}

The CSF concentration of GLP-1 was increased after intraventricular, but not after subdural or intraparenchymal 


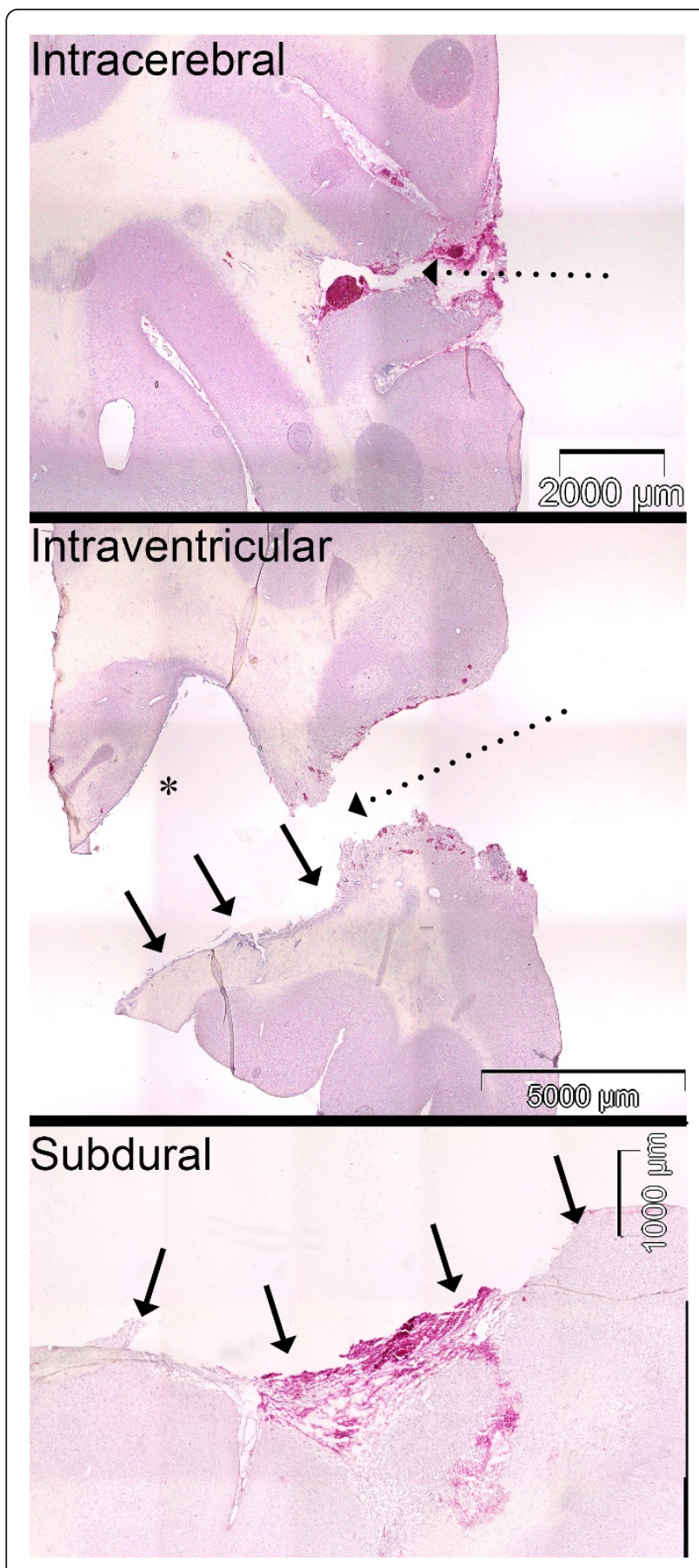

Figure 3 Coronal cross-sections through the implantation site (H\&E stains). Minor fresh haemorrhages, as typical after microsurgery, can be seen at the implantation site (arrows) following the explantation procedure. No major gliotic, inflammatory or necrotic areas are visible. Dashed arrows: surgical approach; ${ }^{*}=$ lateral ventricle

implantation. Histological as well as gross macroscopic examination of the brains and the different implantation sites do not suggest that this is secondary to compartmentalization of the implant from local hemorrhage, glial scarring or significant inflammation. Instead, the present findings provide evidence suggesting that in order to obtain efficient CSF concentration of its products, a cell implant needs sufficient and large exposure to the CSF, and one could argue that this would be obtained after intraventricular implantation.

The histological examination of the cat brains revealed a relative large area of brain tissue damage as the result of the implantation of the mesh bag. A clinical translation of this technique would not result in similar lesions, just because of the much larger anatomical dimensions of the human brain. In fact, in the human brain minimal invasive surgical procedures, i.e. endoscopic surgery could be used for the intraventricular implantation of the cell capsules.

\section{Intraventricular biodelivery with micro-encapsulation techniques}

While the intracerebroventricular administration of trophic factors has influenced the pathology of neurodegenerative disorders [24,2], the rapid clearance of CSF into the venous circulation has been recognized as a substantial limitation to the pharmakokinetics of this drug delivery route $[4,25]$. The only reported clinical study investigating intraventricular, hollow fiber encapsulated cell biodelivery revealed only minimally increased CSF concentration of the delivered factor [9]. The present experiments in a large animal model, however, demonstrate that CSF concentrations up to a therapeutic level can be achieved by ventricular transplantation of cells secreting a soluble factor. This discrepancy can be explained by the different encapsulation technique, i.e. hollow fiber encapsulation $v$ s. micro-encapsulation. Micro-encapsulation, as used in our study, allows for the transplantation of a significantly higher number of cells, i.e. millions compared to only hundreds of thousands in the hollow fiber encapsulation [26-28]. Thus, the higher release rates that can be achieved with the micro-encapsulation technique, compensate for the rapid CSF clearance, and thereby help the build up of pharmacologically active CSF factor concentrations. The viability and secretory capacity of our cells at the time of explantation further suggests that the sustained cell-based production of GLP-1 provides steady-state conditions despite a rapid CSF clearance. Having achieved active CSF levels, substances may diffuse into the brain interstitial fluid through the ependymal layer bordering the ventricles. Substances may also be rapidly moved via CSF flow tracks into the hemispheric subarachnoid space, and from there into the brain tissue along the perivascular spaces by means of a rapid convective transport mechanism [29]. These suggestions are supported by the finding that in primates, neurotrophic growth factor can be widely distributed throughout the brain to areas remote from the ventricular infusion site [30]. As encapsulated cell biodelivery has achieved active CSF levels of a soluble factor, this can be considered 
essential for any pharmacological activity. Nevertheless, because of complex relationships between concentrations in CSF and other brain compartments, CSF concentrations may be difficult to interpret and may have limited value [31]. However, considering our findings in the rodent experiments which showed therapeutic GLP-1 effects after ventricular encapsulated cell biodelivery, GLP-1 might be a prototype for a substance qualified for cell-based delivery into the CSF for the following reasons:

- Its small molecular weight facilitates diffusional and convective distribution through the brain tissue.

- Pharmacological activity is already achieved at considerably low drug concentrations in the picomolar range.

- A sustained delivery may be achieved with encapsulated cell biodelivery.

Despite the controversy about ventricular drug delivery and the discussed pharmacokinetic limitations, there might be a niche in this for encapsulated cell biodelivery of soluble, highly biologically-effective neuropeptides of low molecular weight like GLP-1.

The possibility to explant stem cell transplants from the brain could be an important safety aspect in a clinical application. While retrieval of hollow fibers has been described $[1,6]$, there is currently no non-invasive technique available for the explantation of polymeric microcapsules. Our report is the first to describe a practical technique for the retrieval of microcapsules. We assume that volumetric flow of cerebrospinal or interstitial fluid through the water-permeable mesh permits the diffusional nutrient and oxygen supply for the enclosed cellcontaining capsules. Nonetheless, we are aware that the mesh may hamper the cell viability, particularly if the mesh pores are obstructed with invading cells and fibrin and blood clot layers, a finding well known as a cause for ventricular catheter obstruction. This partial clogging of the mesh pores may therefore be responsible for the observed inter-individual variability of viability and GLP-1 secretion rate seen in these experiments.

\section{Conclusion}

This study has shown that cell-based delivery of soluble factors into the cerebral ventricles can achieve pharmacologically active concentrations in the CSF. This finding provides the rationale to pursue the objectives with ventricular drug delivery, particularly to look for possible therapeutic effects of encapsulated cell biodelivery in large animal models of neurological diseases.

\section{Acknowledgements}

This study was supported by the German Federal Ministry of Education and Research and the Neurobionics Foundation Hannover, Germany.

\section{Author details}

${ }^{1}$ Institute for Laboratory Animal Science and Central Animal Facility, Hannover Medical School, Carl-Neuberg-Str. 1, 30625 Hannover, Germany. ${ }^{2}$ Neurosurgery Foundation, 55 Claverick Str., Providence, RI 02903, USA. ${ }^{3}$ International Neuroscience Institute, Rudolf-Pichlmayrstr. 4, 30625 Hannover, Germany. ${ }^{4}$ CellMed AG, Industriestrasse 19, 63755 Alzenau, Germany.

\section{Authors' contributions}

$\mathrm{SG}, \mathrm{TB}$ and $\mathrm{HJH}$ performed and contributed to the animal experiments; SG, $\mathrm{TB}, \mathrm{MM}$ and PK contributed to conception, data analysis and preparation of the manuscript, and CW and PG developed and manufactured the cell capsules.

All authors have read and approved the final version of the manuscript.

\section{Competing interests}

C.W. and P.G. are employed by CellMedAG and T.B. is consultant to CellMed $A G$, which is the company manufacturing the encapsulated cells.

Received: 28 January 2011 Accepted: 17 May 2011

Published: 17 May 2011

\section{References}

1. Tseng JL, Aebischer P: Encapsulated neural transplants. Prog Brain Res 2000, 127:189-202

2. Thorne RG, Frey WH: Delivery of neurotrophic factors to the central nervous system: pharmacokinetic considerations. Clin Pharmacokinet 2001, 40:907-946.

3. Lo EH, Singhal $A B$, Torchilin VP, Abbott NJ: Drug delivery to damaged brain. Brain Res Brain Res Rev 2001, 38:140-148.

4. Aird RB: A study of intrathecal, cerebrospinal fluid-to-brain exchange. Exp Neurol 1984, 86:342-358.

5. Pardridge WM: Drug transport in brain via the cerebrospinal fluid. Fluids Barriers CNS 2011, 8:7.

6. Lindvall O, Wahlberg LU: Encapsulated cell biodelivery of GDNF: a novel clinical strategy for neuroprotection and neuroregeneration in Parkinson's disease? Exp Neurol 2008, 209:82-88.

7. Buchser E, Goddard M, Heyd B, Joseph JM, Favre J, de Tribolet N, Lysaght M, Aebischer P: Immunoisolated xenogenic chromaffin cell therapy for chronic pain. Initial clinical experience. Anesthesiology 1996, 85:1005-1012.

8. Zurn AD, Henry H, Schluep M, Aubert V, Winkel L, Eilers B, Bachmann C, Aebischer P: Evaluation of an intrathecal immune response in amyotrophic lateral sclerosis patients implanted with encapsulated genetically engineered xenogeneic cells. Cell Transplant 2000, 9:471-484.

9. Bloch J, Bachoud-Levi AC, Deglon N, Lefaucheur JP, Winkel L, Palfi S, Nguyen JP, Bourdet C, Gaura V, Remy P, et al: Neuroprotective gene therapy for Huntington's disease, using polymer-encapsulated cells engineered to secrete human ciliary neurotrophic factor: results of a phase I study. Hum Gene Ther 2004, 15:968-975.

10. Murua A, Portero A, Orive G, Hernandez RM, de Castro M, Pedraz JL: Cell microencapsulation technology: towards clinical application. J Control Release 2008, 132:76-83.

11. Orive G, Hernandez RM, Rodriguez Gascon A, Calafiore R, Chang TM, de Vos P, Hortelano G, Hunkeler D, Lacik I, Pedraz JL: History, challenges and perspectives of cell microencapsulation. Trends Biotechnol 2004, 22:87-92.

12. Perry T, Haughey NJ, Mattson MP, Egan JM, Greig NH: Protection and reversal of excitotoxic neuronal damage by glucagon-like peptide- 1 and exendin-4. J Pharmacol Exp Ther 2002, 302:881-888.

13. Perry T, Lahiri DK, Sambamurti K, Chen D, Mattson MP, Egan JM, Greig NH Glucagon-like peptide-1 decreases endogenous amyloid-beta peptide (Abeta) levels and protects hippocampal neurons from death induced by Abeta and iron. J Neurosci Res 2003, 72:603-612.

14. Heile AM, Wallrapp C, Klinge PM, Samii A, Kassem M, Silverberg G, Brinker T: Cerebral transplantation of encapsulated mesenchymal stem cells improves cellular pathology after experimental traumatic brain injury. Neurosci Lett 2009, 463:176-181.

15. Klinge $P$, Harmening $K$, Miller MC, Heile A, Wallrapp C, Geigle P, Brinker T: Encapsulated native and Glucagon-like peptide-1 transfected human mesenchymal stem cells in a transgenic mouse model of Alzheimer's disease. Neurosci Lett 2011. 
16. Simonsen JL, Rosada C, Serakinci N, Justesen J, Stenderup K, Rattan SI, Jensen TG, Kassem M: Telomerase expression extends the proliferative life-span and maintains the osteogenic potential of human bone marrow stromal cells. Nat Biotechnol 2002, 20:592-596.

17. Beak SA, Heath MM, Small CJ, Morgan DG, Ghatei MA, Taylor AD, Buckingham JC, Bloom SR, Smith DM: Glucagon-like peptide-1 stimulates luteinizing hormone-releasing hormone secretion in a rodent hypothalamic neuronal cell line. J Clin Invest 1998, 101:1334-1341.

18. Drucker DJ: Biological actions and therapeutic potential of the glucagonlike peptides. Gastroenterology 2002, 122:531-544.

19. Campos RV, Lee YC, Drucker DJ: Divergent tissue-specific and developmental expression of receptors for glucagon and glucagon-like peptide-1 in the mouse. Endocrinology 1994, 134:2156-2164.

20. During MJ, Cao L, Zuzga DS, Francis JS, Fitzsimons HL, Jiao X, Bland RJ, Klugmann M, Banks WA, Drucker DJ, et al: Glucagon-like peptide-1 receptor is involved in learning and neuroprotection. Nat Med 2003, 9:1173-1179.

21. Holst JJ: Glucagon-like peptide-1: from extract to agent. The Claude Bernard Lecture, 2005. Diabetologia 2006, 49:253-260.

22. Miyan JA, Zendah M, Mashayekhi F, Owen-Lynch PJ: Cerebrospinal fluid supports viability and proliferation of cortical cells in vitro, mirroring in vivo development. Cerebrospinal Fluid Res 2006, 3:2.

23. Visted T, Lund-Johansen M: Progress and challenges for cell encapsulation in brain tumour therapy. Expert Opin Biol Ther 2003, 3:551-561.

24. Fumagalli F, Racagni G, Riva MA: The expanding role of BDNF: a therapeutic target for Alzheimer's disease? Pharmacogenomics J 2006, 6:8-15.

25. Lo EH, Singhal AB, Torchilin VP, Abbott NJ: Drug delivery to damaged brain. Brain Res Brain Res Rev 2001, 38:140-148.

26. Schwenter F, Schneider BL, Pralong WF, Deglon N, Aebischer P: Survival of encapsulated human primary fibroblasts and erythropoietin expression under xenogeneic conditions. Hum Gene Ther 2004, 15:669-680.

27. Sieving PA, Caruso RC, Tao W, Coleman HR, Thompson DJ, Fullmer KR, Bush RA: Ciliary neurotrophic factor (CNTF) for human retinal degeneration: phase I trial of CNTF delivered by encapsulated cell intraocular implants. Proc Natl Acad Sci USA 2006, 103:3896-3901.

28. Mittoux V, Joseph JM, Conde F, Palfi S, Dautry C, Poyot T, Bloch J, Deglon N, Ouary S, Nimchinsky EA, et al: Restoration of cognitive and motor functions by ciliary neurotrophic factor in a primate model of Huntington's disease. Hum Gene Ther 2000, 11:1177-1187.

29. Guan J, Beilharz EJ, Skinner SJ, Williams CE, Gluckman PD: Intracerebral transportation and cellular localisation of insulin-like growth factor-1 following central administration to rats with hypoxic-ischemic brain injury. Brain Res 2000, 853:163-173.

30. Emmett CJ, Stewart GR, Johnson RM, Aswani SP, Chan RL, Jakeman LB: Distribution of radioiodinated recombinant human nerve growth factor in primate brain following intracerebroventricular infusion. Exp Neurol 1996, 140:151-160.

31. de Lange EC, Danhof M: Considerations in the use of cerebrospinal fluid pharmacokinetics to predict brain target concentrations in the clinical setting: implications of the barriers between blood and brain. Clin Pharmacokinet 2002, 41:691-703.

doi:10.1186/2045-8118-8-18

Cite this article as: Glage et al:: Therapeutic concentrations of glucagonlike peptide-1 in cerebrospinal fluid following cell-based delivery into the cerebral ventricles of cats. Fluids and Barriers of the CNS 2011 8:18,

\section{Submit your next manuscript to BioMed Central and take full advantage of:}

- Convenient online submission

- Thorough peer review

- No space constraints or color figure charges

- Immediate publication on acceptance

- Inclusion in PubMed, CAS, Scopus and Google Scholar

- Research which is freely available for redistribution 